\title{
O TEATRO ENQUANTO ELEMENTO DO ENSINO DE LITERATURA: CONFLUÊNCIAS ARTÍSTICAS E DESCOBRIMENTOS DE SI
}

Jean Michel Valandro ${ }^{1}$

\begin{abstract}
Resumo: Este artigo tem por objetivo dissertar acerca da maneira como o teatro pode auxiliar o ensino de literatura e, consequentemente, promover outros benefícios à educação sociocultural. Para isso, a pesquisa apoia-se na metodologia da revisão bibliográfica, percorrendo caminhos que abordam as confluências entre a performance dramática e suas relaçôes com o texto literário. Como resultados da reflexão que se propóe neste estudo, podem ser citadas a capacidade que o diálogo artísticoliterário tem de desacomodar os corpos docilizados pelo sistema político-econômico que regula a sociedade e impóe um modus operandi rígido aos indivíduos; o aprimoramento de habilidades sociocomunicativas e, ainda, o descobrimento de um novo eu e de novas relaçóes que ele pode estabelecer com os outros com o mundo que o rodeia.
\end{abstract}

Palavras-chave: Arte. Literatura. Teatro. Descobrimento de si.

\section{DRAMA AS AN ELEMENT IN THE LITERATURE TEACHING - ARTISTIC CONFLUENCES AND SELF-DISCOVERY}

\begin{abstract}
This paper aims to lecture about the ways Drama could help Literature teaching and, consequently, how it promotes other benefits to sociocultural education. For this purpose, the research is based on the methodology of bibliographical review and follows some paths that approach the confluences between Drama and its relation with the literary text. As results of the reflection proposed by this study we could quote the ability within the artistic-literary dialogue has to put in motion the bodies meekened by the political-economic system, which regulates society and imposes a rigid modus operandi to the individuals. We could also quote the improvement of social and communicative skills and, in addition, the discovery of a new self as well as of new relationships that he may establish with the others and with the world that surrounds him.
\end{abstract}

Keywords: Art. Literature. Drama. Self-discovery.

1 Graduado em Letras português/inglês pela Universidade do Vale do Taquari - Univates. Pósgraduando em Literatura Contemporânea pela Universidade São Luís EAD. Designer Educacional do Setor de Educação a Distância da Univates. jeanmvalandro@gmail.com 


\section{PRÓLOGO: ABREM-SE AS CORTINAS}

Criar é fazer, mas fazer algo novo, diferente ou recriar a partir do já existente, isto é, ser capaz de utilizar qualquer objeto, por mais insignificante que seja, para chegar a algo distinto. Portanto, a criatividade é toda conduta espontânea, toda conduta que tenha um sotaque pessoal e não meramente repetitivo, será tudo aquilo que possa reconhecer-se a si mesmo, tudo o que se possa simplesmente qualificar como original (POZUELO, 2002, p. 2) ${ }^{2}$.

Desde os primórdios da humanidade, a representação dramática tem sido cara às pessoas em inúmeros momentos. Prova disso são os ritos religiosos, ritos de passagem da juventude para a idade adulta que até hoje se mantêm em alguns povos, a criança imitando seus pais, entre outros. Vale destacar que se entende por representaçáo dramática, aqui, toda e qualquer performance que contemple elementos da teatralidade.

Com o passar dos séculos a dramatização tornou-se uma forma de arte - o teatro -, adquirindo também um caráter mais amplo do que somente aquele cerimonial. Além disso, com o surgimento de diferentes formas de criação literária na cultura ocidental, chegou-se ao gênero dramático, que tem especial relaçáo com o teatro, supramencionado, uma vez que reúne aqueles textos naturalmente passíveis de serem performados.

Esse gênero literário surgiu na Grécia Antiga e forjou uma relação simbiótica entre literatura e teatro. Ele era performado através de subgêneros como a comédia e a tragédia e possuía fins educativos, ensinando valores morais enquanto proporcionava entretenimento às massas. Alguns representantes desse gênero literário foram Sófocles, Eurípedes e Ésquilo. Entretanto, conforme o tempo avançava, as relaçóes entre teatro e literatura extrapolaram esse gênero, de maneira a interagirem de diversas outras maneiras.

Partindo dessa relaçáo dialógica entre duas modalidades de arte ainda presentes na contemporaneidade, este artigo - escrito por um professor licenciado em Letras e com diversas experiências com atuação - visa dissertar acerca das possíveis confluências entre teatro e literatura no ambiente escolar, de modo a refletir sobre a formação de um/a leitor/a crítico/a não só de textos verbais ou gestuais, mas do mundo que o cerca. Para tal, parte-se do pressuposto de que a arte, enquanto elemento curricular, permite o exercício de práticas que oportunizam conhecer-se a si mesmo e, a partir disso, entender o outro e a sociedade.

A fim de versar sobre tais processos, consideraremos como tópico principal a literatura no âmbito escolar e sua relaçáo natural com o teatro, bem como buscaremos responder ao problema deste artigo, que pode ser representado pelo

2 Crear es hacer, pero hacer algo nuevo, diferente o recrear a partir de lo ya existente, es decir, ser capaces de utilizar cualquier objeto, por insignificante que sea, para llegar a algo distinto. Por lo tanto, la creatividad es toda conducta espontánea, toda conducta que tenga un acento personal y no meramente repetitivo, será todo aquello que pueda reconocerse a sí mismo, todo lo que sencillamente pueda calificarse de original (POZUELO, 2002, p. 2). 
seguinte questionamento: de que maneira se desenvolve o ensino de literatura em sala de aula e como o teatro pode colaborar para potencializá-lo? Além disso, falaremos também da importância do teatro enquanto elemento transgressor da perspectiva ocidental de corpo na sala de aula, ainda que de maneira breve.

Além do já mencionado até aqui, vale ressaltar, para um melhor entendimento do panorama geral do artigo, que ele está dividido em seis títulos, cuja redação está intimamente relacionada à dinâmica do teatro. São eles: Prólogo: abrem-se as cortinas (que é esta introdução); Primeiro ato: o ensino de literatura - texto ou pretexto?; Segundo ato: provocando o corpo do leitor-ator-discente a viver a arte - sobre a disciplina na sala de aula; Terceiro ato: das potências do teatro enquanto ferramenta didática; Quarto ato: a sala de aula como lócus de confluências entre o teatro e a literatura e Epílogo: "o resto é silêncio". Ainda, a metodologia utilizada neste estudo é a revisão bibliográfica, que compreende a utilização de fontes como artigos e livros cuja pertinência temática esteja ligada ao assunto pesquisado (MARCONI; LAKATOS, 2010; GIL, 2008).

Dito isso, na sequência apresenta-se um panorama sobre o ensino de literatura no âmbito escolar.

\section{PRIMEIRO ATO: O ENSINO DE LITERATURA - TEXTO OU PRETEXTO?}

Não é incomum ouvir de diversas pessoas a frase "Eu era péssimo em Literatura! Minhas aulas eram bem ruins", ou então "Literatura é algo difícil de entender!". Acredita-se que tal atitude frente à literatura pode estar relacionada ao fato de haver diversos profissionais da educação que adotam metodologias de ensino de literatura bastante normativas, ou a programas de educação que não levam em conta a realidade social do/a aluno/a, escolhendo suas leituras com base na obrigatoriedade delas em processos seletivos de universidades ou de concursos.

Além disso, não se pode esquecer de mencionar os fatores sociais que ajudam a construir uma visão negativa em torno da arte, pois aquilo que ela ensina não é entendido pela maioria das concepçóes político-econômicas contemporâneas como algo que possua caráter prático e de aplicação imediata na realidade do indivíduo. Apesar disso, defende-se a ideia de que a arte possui açôes perceptíveis, mas elas estâo mais relacionadas a aspectos subjetivos, ou seja, não materiais.

Devido a essa teia de complexidades, pode-se dizer que

o ensino de literatura na escola é um tema complexo, que tem sido abordado a partir de diferentes perspectivas e que, apesar dos aportes até hoje oferecidos, segue em constante elaboração, pois não foi possível definir um método universal que tenha êxito em todos os contextos e com todos os sujeitos. Todavia, têm surgido reflexóes acerca de seu ensino que aclaram o papel da 
literatura na escola e a maneira com que ela deve ser concebida e abordada (MUÑOZ, 2013, p. 11-12, tradução livre) $)^{3}$.

Isto é, quando se fala do ensino de literatura, um escopo específico não é algo simples de delinear e tampouco é fácil atribuir-lhe algum caráter de praticidade, como se consegue fazer mais imediatamente com outros componentes curriculares, visto que o trabalho com o texto literário conversa mais profundamente com elementos socioculturais formadores de subjetividades. Porém, um objetivo de aprendizagem, decorrente de uma das competências definidas para a área das Linguagens na Base Nacional Comum Curricular - BNCC (BRASIL, 2018, texto digital), que parece resumir bastante daquilo que a literatura escolar busca fazer é o seguinte: "analisar e compreender as circunstâncias sociais, históricas e ideológicas em que se dão diversas práticas e discursos".

Contudo, de acordo com Cardoso (2006, p. 181), a questão é que esse ensino de literatura que prevê o desenvolvimento da consciência social, bem como a fruição atinente às artes, segue sendo cerceado pelo fato de que a quantidade de leituras sobrepuja a qualidade delas, às vezes não no sentido de qualidade enquanto obra literária em si, mas com relaçáo à capacidade de conversar com os conhecimentos do/a aluno/a e proporcionar o prazer necessário para que ele/a consiga fruir e apreciar esteticamente o texto que tem à sua frente.

Isso para não mencionar os casos em que "o ensino da literatura na escola tem se caracterizado mais por estudos sobre a literatura -, ou mais particularmente sobre a história da literatura, a partir da categoria 'estética literária' - que por práticas de contato efetivo com o texto literário" (BARBOSA, 2011, p. 149). Essa perspectiva de trabalho didático aniquila potencialmente a possibilidade de entender o livro enquanto obra de arte que deve ser apreciada, já que ele é reduzido a um pretexto para estudar determinado período literário ou outro aspecto dessa mesma natureza normativa e encaixotadora de conceitos.

Defende-se que essa perspectiva classificatória de estudo da literatura deva ser refutada, pois a ideia de se estudar áreas originalmente do campo das artes, como se mencionou anteriormente, é fazer pensar, atribuindo sentido ao que se é e conhecendo melhor seus pontos fortes, seus limites, a fim de criar relaçōes com o próximo e com o ambiente que nos tornem mais sensíveis e críticos às questóes que envolvem a sociedade como um todo. Tal perspectiva encontra respaldo em Larrosa (2002, p. 21), que afirma que pensar criticamente relaciona-se de alguma forma com as palavras, através das quais assumimos determinados posicionamentos no mundo, uma vez que "o homem é um vivente com palavra [...] se dá em palavra,

3 La enseñanza de la literatura en la escuela ha sido un tema complejo que se ha abordado desde diferentes perspectivas y que, a pesar de los aportes hasta hoy brindados, sigue en constante elaboración, pues no ha sido posible definir una forma universal que resulte exitosa en todos los contextos y sujetos. Sin embargo, alrededor de su enseñanza, han surgido reflexiones que clarifican el papel de la literatura en la escuela y la manera en la que ésta debe ser concebida y abordada (MUNOZZ, 2013, p. 11-12). 
está tecido de palavras" e, sendo a literatura a arte da palavra, está defendida a tese de por que ensiná-la.

Dado o exposto, considera-se que o programa de estudos ideal para a literatura é aquele que considera tanto os cânones quanto outras obras que "conversem" com a realidade do aluno, fazendo-o entender a importância de ambas. Isso porque, voltando à premissa das palavras supracitadas, pode-se entender que diferentes públicos tenham diferentes dizeres e soa mais confortável e acolhedor partir de textos que utilizem a "língua" do público discente para ir avançando em direção a leituras relativamente mais complexas e metafóricas.

Tendo falado sobre o ensino de literatura, vamos tratar, na sequência, da sala de aula em que ele acontece, e entender de que forma ela age sobre os corpos dos/ as estudantes.

\section{SEGUNDO ATO: PROVOCANDO O CORPO DO LEITOR-ATOR- DISCENTE A VIVER A ARTE - SOBRE A DISCIPLINA NA SALA DE AULA}

Normalmente, quando se pensa em sala de aula, a imagem que chega à mente da maioria das pessoas é aquela de classes e cadeiras todas enfileiradas, uma atrás da outra. Isso porque, durante muito tempo, a estrutura da sala de aula permaneceu a mesma, motivo pela qual essa pintura temporal permeia a memória de diferentes geraçóes praticamente inalterada.

Essa configuração, quando somada a um ensino classificatório da literatura como o mencionado anteriormente, é reguladora da criatividade e da expressão, inibindo-as, de modo que, dessa forma, as aulas tornam-se uma espécie de "linha de produçáo, onde a atividade do homem é reduzida a algumas açóes de rotina, dentro de um ritmo determinado [...] [porque, nessa perspectiva], durante a aula os corpos devem ser disciplinados" (KOUDELA, 1999, p. 122). Esse método, que envolve um fazer pedagógico mais mecânico e anestesiante dos corpos e que se propaga há bastante tempo, indica que "uma relação de fiscalização, definida e regulada, está inserida na essência da prática do ensino: não como uma peça trazida ou adjacente, mas como um mecanismo que lhe é inerente, e multiplica sua eficiência" (FOUCAULT, 2004, p. 158).

Com base nesses fatos, ainda segundo Koudela (1999), cabe afirmar que os princípios organizadores da sociedade atual frequentemente levam o indivíduo a entender e perceber seu corpo somente como algo negativo, voltado a doenças, estresse, cansaço. Essa concepção é fruto, principalmente, dos modos de vida das sociedades ocidentais, que não têm por costume a consciência corporal como a de outras culturas que não se baseiam em epistemologias fundadas na separação entre corpo e mente.

É a partir dessa realidade que se afirma que o teatro, enquanto arte performática, pode ter um papel transformador e transgressor de paradigmas, uma vez que tensiona os fundamentos ocidentais sobre o qual estão calcadas as concepçóes de corpo. Assim, propondo práticas desafiadoras e provocando o/a discente a sair da 
sua zona de conforto é que as atividades contemplando essa arte pretendem romper com a inércia socialmente infundida nos/as aprendizes e reforçada pela escola, que

geralmente impede a criança de expressar espontaneamente seu mundo. $\mathrm{O}$ conceito espontâneo muito pouco é trabalhado nas escolas, os conceitos científicos já estão prontos, portanto são mais simples de serem transmitidos. toda a expressão falada é reprimida, em geral, severamente (GIL, 1991, p. 58).

No entanto, vale ressaltar que o teatro não é algo que normalmente entra na grade curricular das escolas - nem mesmo no componente curricular de Artes -, talvez por se compreender que ele deva fazer parte do núcleo de temas transversais, que perpassa todas as áreas, ou então por entendê-lo como um conhecimento acessório, ou ainda porque as concepçóes socioculturais julgam que ele deva ser uma prática educativa não escolarizada. Por isso, defende-se, neste artigo, a importância da prática do teatro nas aulas de literatura, que é um campo do saber com espaço garantido no currículo escolar e também pela relação de proximidade que ambas as artes apresentam, desde os primórdios da humanidade, como mencionado na introdução deste texto.

\section{TERCEIRO ATO: DAS POTÊNCIAS DO TEATRO ENQUANTO FERRAMENTA DIDÁTICA}

Para iniciar, cabe salientar que a prática do teatro está embasada pela BNCC, visto que contempla diversas competências e habilidades da área das linguagens e suas tecnologias que se deseja que o aluno desenvolva. Nessa perspectiva, uma das habilidades diz que o educando deve aprender a "utilizar as diversas linguagens (artísticas, corporais e verbais) em diferentes contextos, valorizando-os como fenômeno social, cultural, histórico, variável heterogêneo e sensível aos contextos de uso" (BRASIL, 2018, texto digital).

Porém,

o grande problema da sociedade em que vivemos é que não sabemos escutar. Talvez tenhamos criado essa surdez como refúgio frente à invasão de mensagens que nos assediam continuamente, enviadas por alguém que, de fato, tem, sabe e possui meios para emiti-la. $\mathrm{O}$ abuso de meios audiovisuais, ao mesmo tempo que informa suas mentes [dos jovens], vai deformando sua expressividade. $\mathrm{O}$ jovem viciado em telas de agora não brinca, não ri, náo compete com os demais: o faz com e contra a máquina, contra o videogame, contra o computador. Ele deixou de ser um emissor de emoçóes para se converter em um mero receptor... e , tristemente, não de seus conhecimentos e ideias naturais, próprias de sua evolução, mas de outras exteriores, inculcadas subliminar e programadamente por pessoas que não pretendem educar com valores. Nunca na história o jovem esteve melhor atendido e mais abandonado. Por isso, temos de buscar uma atividade artística que respeite e potencialize a expressividade de nossos alunos, mas que os faça saber que, além da sua, 
existem outras opiniôes igualmente respeitáveis (RUBIO, 2001, texto digital, tradução livre $)^{4}$.

Nesse sentido, o trabalho com o teatro na sala de aula, ou mesmo a iniciação aos jogos teatrais é de extrema importância, pois, de acordo com Neves e Santiago (2009), os jogos teatrais culminam no desenvolvimento de representaçóes que evocam e manipulam diversos signos, sejam eles verbais ou não, que se convertem em instrumentos fundamentais para o desenvolvimento da inteligência verbal, emocional, intra e interpessoal.

Isto é, levar o teatro para dentro da sala de aula é fator desencadeador de mudanças, pois impulsiona o/a educando/a a crescer como pessoa e a desenvolverse culturalmente, visto que ele/a exercita a comunicaçáo por meio da linguagem teatral, improvisando de maneira lúdica (NEVES; SANTIAGO, 2009).

Dito isso, e considerando a ideia de que o/a jovem da atualidade não interage tanto de forma presencial com os/as demais, senão por meio das máquinas, é importante saber que o teatro, além do já apresentado, demonstra a impossibilidade de isolamento. Tal afirmação tem como base o fato de que, ao atuar, depende-se do outro e é necessário desenvolver uma escuta e um olhar atentos que considerem também os silêncios e descubram quando é preciso comunicar-se e quando se deve ceder a vez para o colega. Essa relaçáo que se estabelece acontece, inclusive, entre quem atua e o público, de maneira que, mesmo se tratando de um monólogo, a interação sempre está presente.

O teatro, então,

no plano individual, proporciona o desenvolvimento de suas capacidades expressivas e artísticas; no plano coletivo, por ser uma atividade grupal, oferece o exercício das relaçóes de cooperação, diálogo, respeito mútuo, reflexão sobre como agir com os colegas, flexibilidade de aceitação das diferenças e aquisição de sua autonomia, como resultado de poder agir e pensar com maior "liberdade" (CAMARGO 2003, p. 39).

Dessa forma, ao interagir, trabalha-se ainda a questão da adaptação, que é uma habilidade bastante apreciada a nível de relacionamento social em diversos ambientes e situações. Logo, é possível entender que os jogos/atividades teatrais

4 El gran problema de la sociedad en la que vivimos es que no sabemos escuchar. Tal vez hayamos generado esta sordera como refugio ante la invasión de mensajes que nos acosan continuamente, enviados por alguien que sí tiene, sabe y posee medios para emitir. La actitud de nuestros escolares ha sufrido un acentuado viraje hacia horizontes hasta hace poco insospechados. El abuso de medios audiovisuales, si bien informa sus mentes, va deformando su expresividad. El niño teleadicto de ahora no juega, no ríe, no compite con los demás: lo hace con y contra la máquina, contra el videojuego, contra el ordenador. Ha dejado de ser un emisor de emociones para convertirse en un mero receptor... y, tristemente, no de los conocimientos y las ideas naturales, propias de su evolución, sino de otras exteriores, inculcadas subliminal y programadamente por personas que no pretenden educar en valores. Nunca en la historia ha estado el niño mejor atendido y más abandonado. Por ello hemos de buscar una actividad artística que respete y potencie la expresividad de nuestros alumnos, pero que les haga saber que, además de la suya, existen otras opiniones igualmente respetables (RUBIO, 2001, texto digital). 
são capazes de extrapolar os muros da escola e permitir um intercâmbio de valores sociais que são tratados como alegorias na prática da representação para, depois, fazerem parte de um processo de reflexão sobre o que é fazer parte de determinada sociedade, em determinadas configuraçôes de tempo e espaço.

Também, conforme ensinam Neves e Santiago (2009), as performances de teatro podem adquirir um caráter terapêutico, ajudando a lidar, inclusive, com questóes da subjetividade oriundas do fracasso escolar. Isso decorre do fato de que o teatro permite que o/a aluno/a se expresse livremente e percebam-se nuances emocionais que normalmente ele/a náo demonstraria em outros momentos da aula, porque, muitas vezes, o fracasso escolar deixa marcas que não são facilmente notadas.

\section{QUARTO ATO: A SALA DE AULA COMO LÓCUS DE CONFLUÊNCIAS ENTRE O TEATRO E A LITERATURA}

Ao pensar na prática teatral inserida nas aulas de literatura, sabemos que muito provavelmente o/a professor/a que propóe a atividade é licenciado em Letras, não em Artes Cênicas ou em áreas similares. Mas é possível, entáo, haver uma proposta de trabalho de qualidade com o teatro nas aulas de literatura sendo que o professor não é graduado nesta área? De acordo com Reverbel (1997) e Ferreira (2001) é possível, sim! Segundo as autoras, não é necessário que a pessoa seja graduada na área, porém, é necessária uma vasta preparação prévia e estudo extensivo e contínuo sobre as práticas teatrais, a fim de adquirir carga teórica que justifique as escolhas didáticas.

Além disso, considerando o panorama do ensino da literatura apresentado no início deste artigo, o teatro aliado ao trabalho com textos literários é capaz de ajudar a preencher as lacunas deixadas por uma ou outra forma de ensino que não estejam tão adequadas ao grupo discente. Isso porque

[...] o teatro pode chegar a ser uma ferramenta excepcional para canalizar certas tendências educativas que não tenham sido tão efetivas. Com o teatro, os alunos e alunas podem descobrir uma nova forma de aprender divertindose e integrando-se em um grupo, o que faz com que eles reflitam sobre uma multiplicidade de questôes vitais (RODRÍGUEZ, 2013, p. 32, tradução livre $)^{5}$.

A partir das Artes Cênicas, por exemplo, se estabeleceu um vínculo com a literatura, cujas tessituras já existiam desde o surgimento do gênero dramático, embora em outras dimensóes e com propósitos levemente diferentes. Essa relação emerge, na atualidade, como possibilidade de transformar o texto narrativo em vivência, com foco na coletividade e companheirismo entre os aprendizes

5 [...] el teatro puede llegar a ser una herramienta excepcional para encauzar ciertas tendencias educativas que no han sido efectivas. Con el teatro, los alumnos y alumnas pueden descubrir una nueva forma de aprender divirtiéndose e integrándose en un grupo, lo que hace que éstos reflexionen sobre multitud de cuestiones vitales (RODRÍGUEZ, 2013, p. 32) 
(MOTOS, 2009; MUÑOZ, 2013; RODRÍGUEZ, 2013). Essa inter-relação entre as artes também tem se demonstrado frutífera no sentido de desenvolver habilidades socioemocionais como a empatia e a autoestima, para além de reforçar a memória física e/ou vocabular, uma vez que é necessário, em menor ou maior proporçấo, memorizar um texto, dando vida a ele por meio de escolhas do repertório corporal do/a aluno/a em questáo.

Ademais, cognitivamente falando, diversos pesquisadores como McNamee, McLane, Cooper, e Kerwin (2006) descobriram que as estruturas mentais necessárias para processar o drama, ou seja, a representação alegórica proposta pelo teatro, são as mesmas utilizadas na leitura de um texto verbal na modalidade escrita. Isso porque $\mathrm{o}$ ato de ler sugere o estabelecimento de uma relaçáo íntima entre o/a autor/a e o/a leitor/a, pois mesmo que eles/as náo interajam pessoalmente, a imanência do ser está contida nas palavras compreendidas e interpretadas a cada passada de olho sobre o papel (ou sobre a tela... do celular, do computador etc.).

Já o processamento da dramatização exigiria os mesmos mecanismos, como já informado, porém os elementos que estabelecem relação entre si são outros: o/a aluno/a e o/a professor/a. Nessa perspectiva, o processamento envolve, para além das palavras, o imaginário, por meio do qual se estabelecem links e transaçóes espontâneas entre os indivíduos ao interagirem utilizando instrumentos próprios da dramaticidade (SCHNEIDER; JACKSON, 2000).

\section{EPÍLOGO: “O RESTO É SILÊNCIO”“}

Ao finalizar este artigo, vale destacar que as concepçóes aqui defendidas são frutos de construtos didático-metodológicos de um profissional de Letras que, no espaço de quatro anos, promoveu intervençóes em escolas, trabalhando com o letramento literário em turmas de diversas etapas do Ensino Básico. Por isso, elas refletem também muitas das situaçóes experienciadas, que foram permeadas por incertezas, tentativas e erros e inúmeras (re)adequaçóes das proposiçóes, que certamente estáo intimamente ligadas ao delineamento do perfil do profissional docente.

Através das teorias aqui apresentadas, que foram todas testadas em sala de aula ao longo do espaço de tempo supramencionado, percebeu-se que o teatro e a literatura têm o poder de transformar os indivíduos e transgredir determinados padrôes categorizadores, assumindo também um caráter humanizador que favorece o desenvolvimento do espírito de coletividade e das relaçóes de alteridade; melhora os níveis de empatia; promove a desinibição; e qualifica as relaçóes intrapessoais, além de desenvolver o olhar crítico sobre a sociedade por meio de representaçóes alegóricas. Porém, é necessário, primeiramente, estar disposto a abraçar esta

6 A frase "O resto é silêncio" é a última proferida por Hamlet antes de ele morrer envenenado, na peça homônima, escrita por William Shakespeare. 
mudança, mesmo que se comece somente dando a mão a ela e, aos poucos, vá-se aproximando.

Para finalizar, dado todo o exposto, entende-se que, independente da metodologia de ensino de literatura adotada pela escola, fazê-la dialogar com outra arte, no caso, o teatro, é trabalhar em prol do crescimento sociocultural do educando, visto que ter contato com a performance dramática é algo que dificilmente mantém o indivíduo em seu estado inicial. Isso porque, à medida que ele se deixa ser afetado pelos outros, pelo ambiente e se liberta do modus operandi que a sociedade lhe impóe diariamente, ele percebe que existem outras maneiras de ser, de estar e que, para além de ser ator de sua própria realidade, ele pode também ocupar o lugar de diretor da própria peça.

\section{REFERÊNCIAS}

BARBOSA, Begma Tavares. Letramento literário: sobre a formação escolar do leitor jovem. Educ. foco, Juiz de Fora, v. 16, n. 1, p. 145-167, mar./ago. 2011.

BRASIL. Base Nacional Comum Curricular: educação é a base, 2018. Disponível em: http://basenacionalcomum.mec.gov.br/abase/. Acesso em: 29 abr. 2021.

CAMARGO, Maria Aparecida Santana. Teatro na escola: a linguagem da inclusão. Passo Fundo: UPF, 2003.

CARDOSO, Rosimeiri Darc. Livrarias e escolas: espaços de mediação. In: AGUIAR, Vera Teixeira de; MARTHA, Alice Áurea Penteado (orgs.). Territórios da literatura: da literatura aos leitores. São Paulo: Cultura Acadêmica, 2006. p. 165-183.

FERREIRA, Sueli (org.). O ensino das artes: construindo caminhos. Campinas: Papirus, 2001.

FOUCAULT, Michel. Os recursos para o bom adestramento. In: FOUCAULT, Michel.

Vigiar e punir: nascimento da prisão. 29. ed. Petrópolis: Vozes, 2004. p. 153-72.

GIL, Antonio Carlos. Métodos e técnicas de pesquisa social. São Paulo: Atlas, 2008.

GIL, João Pedro de Alcântara. O significado do jogo na Educação Infantil. Dissertação

(Mestrado em Educação) - Universidade Federal de Santa Maria, Santa Maria, 1991.

KOUDELA, Ingrid Dormien. Texto e jogo: uma didática brechtiana. São Paulo:

Perspectiva, 1999.

LARROSA, Jorge. Notas sobre a experiência e o saber de experiência. Rev. Bras. Educ., Rio de Janeiro, n. 19, p. 20-28, jan./abr. 2002. Disponível em: https://www.scielo.br/pdf/ rbedu/n19/n19a02.pdf. Acesso em: 28 abr. 2021.

MARCONI, Marina de Andrade; LAKATOS, Eva Maria. Fundamentos de metodologia científica. 7. ed. São Paulo: Atlas, 2010. 
MATTOS, Mauro Gomes de; ROSSETTO JUNIOR, Adriano José; BLECHER, Shelly. Metodologia da Pesquisa em Educaçáo Física: construindo sua monografia, artigos e projetos. 3. ed. São Paulo: Phorte, 2008.

MCNAMEE, Gillian Dowley; MCLANE, Joan B.; COOPER, Patricia M; KERWIN Sheila M. Cognition and affect in early literacy development. Early Childhood Development and Care, v. 20, n. 4, p. 229-244, ago. 2006. Disponível em: https://www. tandfonline.com/doi/abs/10.1080/0300443850200402. Acesso em: 28 abr. 2021.

MOTOS, Tomás. El teatro en la educación secundaria: fundamentos y retos. Creatividad y sociedad, Madrid, n. 14. p. 1-35, dez. 2009. Disponível em: http://centroderecursos. alboan.org/ebooks/0000/0847/5_APY_REE_2.pdf. Acesso em: 28 abr. 2021.

MUÑOZ, Natalia Suaza. La enseñanza de la literatura en la escuela: una intervención desde el teatro y las artes plásticas. 84f. Monografia (Graduação em Educação Básica com ênfase em Língua Castelhana) - Universidad de Antioquia, Medellín, 2013. Disponível em: http://ayura.udea.edu.co:8080/jspui/bitstream/123456789/1578/1/PA0793.pdf. Acesso em: 28 abr. 2021.

NEVES, Libéria Rodrigues; SANTIAGO, Ana Lydia B. O uso dos jogos teatrais na educação: possibilidades diante do fracasso escolar. Campinas: Papirus, 2009.

POZUELO, Cristina Vacas. Importancia del teatro en la escuela. Revista de innovación y experiencias educativas, n. 16, mar. 2009. Disponível em: http://www.csi-csif.es/ andalucia/modules/mod_ense/revista/pdf/Numero_16/CRISTINA_VACAS_2.pdf. Acesso em: 28 abr. 2021.

REVERBEL, Olga. Oficina de teatro. Porto Alegre: Kuarup, 1997.

RODRÍGUEZ, Julio C. Llamas. ¿Por qué es aconsejable que los alumnos representen obras teatrales en la Educación Primaria? ARTSeduca, n. 4, p 32-36, jan. 2013.

Disponível em: https://dialnet.unirioja.es/descarga/articulo/4182394.pdf. Acesso em: 28 abr. 2021.

RUBIO, Petra-Jesús Blanco. El teatro de aula como estrategia pedagógica: proyecto de innovación e investigación pedagógica. Bilbao: Biblioteca Virtual Miguel de Cervantes, 2001. Disponível em: http:/www.cervantesvirtual.com/obra/el-teatro-de-aula-comoestrategia-pedagogica-proyecto-de-innovacion-e-investigacion-pedagogica--0/. Acesso em: 28 abr. 2021.

SCHNEIDER, Jenifer Jasinki; JACKSON, Sylvia A. W. Process drama: a special space and place for writing. The Reading Teacher, v. 54, n. 1, p. 38-51, set. 2000. 